\title{
Reducing Case Fatality from Acute Myocardial Infarction in Cienfuegos, Cuba, 1994- 2009
}

\author{
Víctor René Navarro MD PhD, Arelys Falcón MD MS, Marcos D. Iraola MD, Francisco Valladares MD MS, \\ Pedro O. Ordúñez MD PhD
}

\begin{abstract}
Between 1994 and 2009, the Dr Gustavo Aldereguía University Hospital of Cienfuegos, Cuba implemented a series of interventions that reduced acute myocardial infarction case fatality rate from $47 \%$ to $15 \%$. These interventions were part of an institutional plan for myocardial infarction included in the hospital's overall quality assurance strategy. Outcomes resulted primarily from organizational changes (from upgrading of the hospital emergency department and provincial emergency system to creation of a comprehensive coronary care unit and a chest pain center); optimizing use of effective drugs (streptokinase, aspirin, ACE inhibitors and beta blockers); adherence to clinical practice guidelines; and continual and participatory evaluation and adjustment.
\end{abstract}

KEYWORDS Acute myocardial infarction, hospital mortality, case fatality rate, health care quality assurance, management quality circles, institutional practice, guideline adherence, clinical practice guideline

\section{INTRODUCTION}

A century ago, only $10 \%$ of deaths were caused by cardiovascular events, while today these events account for almost half the deaths in the developed world and $25 \%$ of those in developing countries. By 2020, they will be responsible for 25 million deaths annually, and coronary heart disease will surpass infectious diseases as the main cause of death and disability.[1]

In Cuba, heart disease is the leading cause of death, with acute myocardial infarction (AMI) the chief contributor.[2,3] This situation, shared with first-world nations, is influenced by Cuba's level of social development and the soundness of its health system, responsible for eliminating infectious diseases as main causes of morbidity and mortality.[4]

During the 1970 s and 1980 s, mortality rates and absolute numbers of deaths from ischemic heart disease in Cuba remained high due to, among other factors, changes in risk factor distribution in the case of rates and population aging in the case of numbers. Ischemic heart disease mortality rates began to fall in the 1990s.[2] This decline has been attributed to the introduction in 1995 of the national control program for ischemic heart disease, the family medicine program based on the primary health care (PHC) network and intrasectoral efforts in health promotion and disease prevention.[4]

Statistics for Cienfuegos province show a similar decline in mortality rates from heart disease (from 191 per 100,000 population in 1999 to 108 per 100,000 in 2009). However, values for the province historically have been higher than the national average. [2] And, notwithstanding declining mortality rates, the number of admissions for AMI at the Dr Gustavo Aldereguía University Hospital (HGAL, the Spanish acronym), the province's secondary care center, continued to grow during this period.[2,5]
The main problem associated with AMI at HGAL in the early 1990s was the high hospital case fatality rate, which was over $50 \%$ in 1992.[5] The rising case fatality rate prompted design of a series of interventions to address case fatality and other indicators of quality of medical attention for AMI. This set of initiatives, ongoing since 1994-which we refer to as HGAL's institutional AMI plan-was undertaken under the aegis of the hospital's new quality assurance system.[6] Their impact was systematically assessed on an ongoing basis, with adjustments made according to results observed.

The objective of this article is to describe the chronological implementation of an institutional plan to reduce AMI case fatality at HGAL in the framework of the hospital's quality management strategy.

\section{IMPLEMENTATION}

Cienfuegos is one of 15 provinces in Cuba, with a population of 402,000 and a landmass of $4178 \mathrm{~km}^{2}$. Its health care network has a two-tier structure: secondary (hospital) and primary health care $(\mathrm{PHC})$, the latter consisting of neighborhood family doctorand-nurse offices and community-based polyclinics offering comprehensive care. The province has a single hospital for adults, HGAL, which provides general, but not pediatric, services. HGAL has 640 beds, admits 22,000 patients per year and has been operating without interruption since 1979.

Figure 1 provides a schematic outline of actions relevant to AMI management taken by HGAL and Cuba's Ministry of Public Health (MINSAP, the Spanish acronym) between 1994 and 2009. Each action taken was independent but linked to those that preceded it. Information from evaluation of each step was iteratively fed into the ongoing assessment of the institutional strategy, prompting changes if necessary. Thus, in addition to describing the particular situation that triggered the action, we describe the principal methodological elements.

Data for calculating case fatality rates during the period were taken from HGAL's monthly statistical reports for the period 19912009[5] (accuracy corroborated by annual autopsy rates of over $80 \%$ ). The study universe consisted of all hospital patients with a diagnosis of AMI during the period. Provincial mortality information was taken from annual statistical reports by MINSAP.[2]

AMI case fatality (Figure 2) was reduced from some $50 \%$ in the early 1990s to $14-15 \%$ after 2005 . In the authors' view, the steady decline had three pivotal moments:

- after 1997, associated with work emphasizing adherence to the AMI clinical practice guidelines (CPG)[7,8] and upgrading of hospital emergency services and the provincial emergency system with MINSAP creation of the Integrated Emergency Medical System (SIUM, the Spanish acronym), which involved integrating administrative, teaching and scientific functions 
Figure 1: Main initiatives in management of acute myocardial infarction, Dr Gustavo Aldereguía Lima University Hospital, Cienfuegos, Cuba, 1994-2009

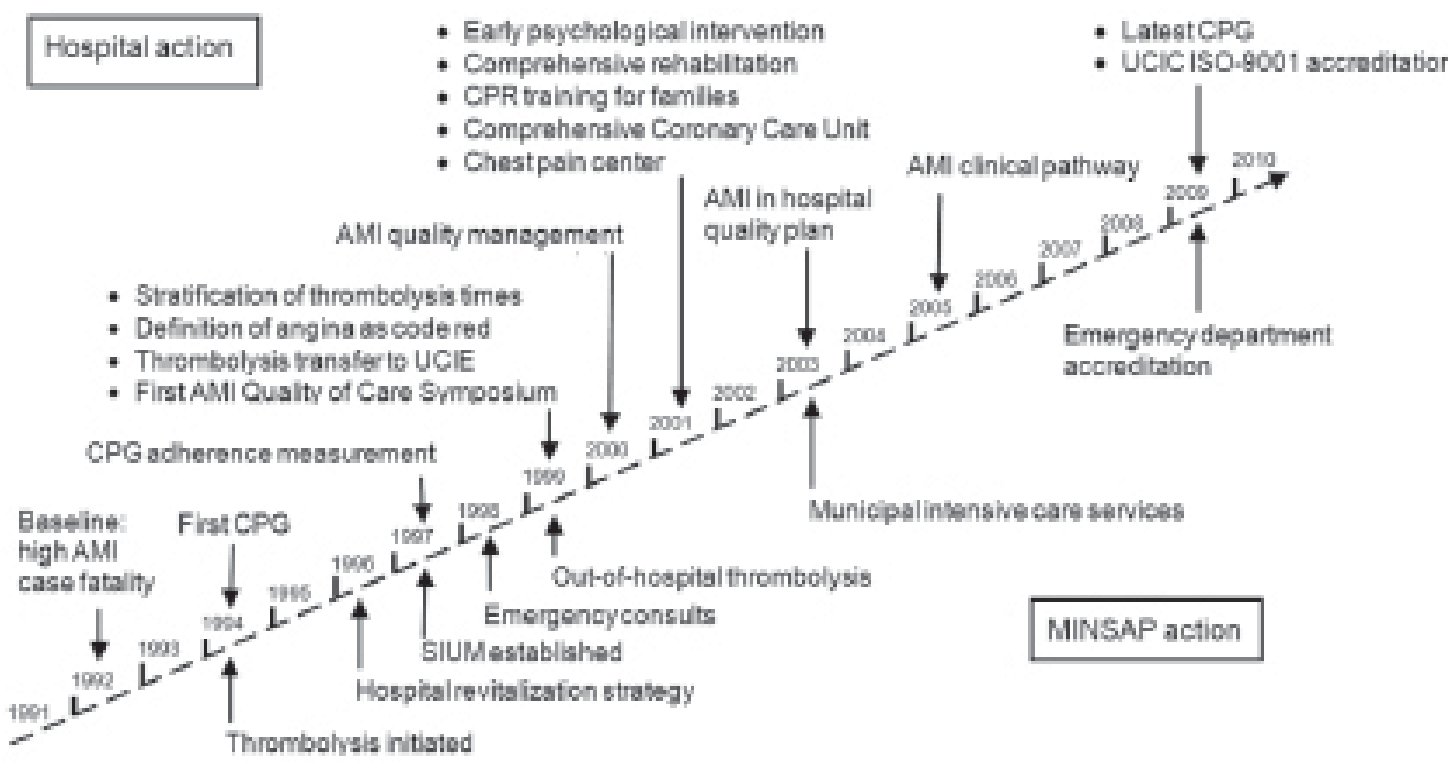

AMI: Acute myocardial infarction CPG: Clinical practice guideline MINSAP: Ministry of Public Health SIUM: Integrated Emergency Medical System UCIC: Comprehensive Cardiac Care Unit UCIE: Emergency Intensive Care Unit

related to critical and emergency care, including mobile emergency medical service, throughout the entire chain of care;

- after 1999, associated with scaling up and faster administration of thrombolytics; and

- after the 2001 opening of HGAL's Comprehensive Cardiac Care Unit (UCIC, the Spanish acronym), facilitating a more comprehensive approach to AMI management. Although MINSAP also introduced more general policies and actions to reduce deaths from diseases that constitute public health problems (Figure 1), many of these were already being carried out at HGAL as part of the work reported here, with new MINSAP directives incorporated as they emerged.

Clinical practice guidelines In 1994, with the objective of standardizing AMI management, clinical practice guidelines were drawn up with methodologies based on expert opinion and group techniques-guidelines that are periodically updated. At first, CPG design and implementation did not alter case fatality rates or any other indicators. Thus, the need to bridge the knowledge-practice gap became evident, and the next step was to evaluate guideline adherence and then increase it. This process was two-pronged: first, each patient's treatment was reviewed daily at the end of each shift in the service where care was provided; and second, every month, a group of evaluators sent a CPG adherence report to the head of the service and the hospital administration. The hospital's AMI management group then decided what further action to take.

In 1997, HGAL began measuring adherence as part of its overall quality assurance system. An initial report for March through August 1997 concluded that CPGs were inadequately applied in $64.3 \%$ of cases, a situation that was associated with a higher risk of death, with a case fatality rate of $61.5 \%$ (RR 3.00, Cl 95\%: 2.235.30). Errors in CPG application associated with higher case fatality were: failure to observe patients with precordial pain but with normal electrocardiograms in hospital; failure to perform electrocardiograms on patients with atypical pain but who also had coronary risk factors; and initial admission of patients to the Intermediate Care Unit instead of UCIC. Another study from January through May 2005[8] showed a higher percentage of good adherence (88.5\%) and lower case fatality; precise definition of adherence required prognostic stratification, ergometry, and an echocardiogram prior to hospital discharge.

As part of the CPG adherence improvement cycle, an AMI clinical pathway was drawn up in 2004[9] and implemented in 2005. [10] The clinical pathway is an instrument for planning and coordinating the sequence of medical, nursing, and administrative procedures (diagnostic testing, consultations, staff training, discharge planning, etc.) necessary for optimum efficiency in care. Núñez[10] showed that with its use, the thrombolysis index was higher ( $80.7 \%$ of patients vs. $53.5 \%$ of those with whom it was not used), adherence to the recommended drug regimen (aspirin and beta blockers) was higher and began earlier, and hospital stays were shorter (6.59 days vs. 8.30). Use of the clinical pathway in $\mathrm{UCIC}$ facilitated adherence to the treatment strategy spelled out in the CPG and later served as an indicator for the cardiology service's quality assurance plan.

Figure 2: Acute myocardial infarction case fatality rates*, Dr Gustavo Aldereguía university Lima Hospital, Cienfuegos, Cuba, 1991-2009

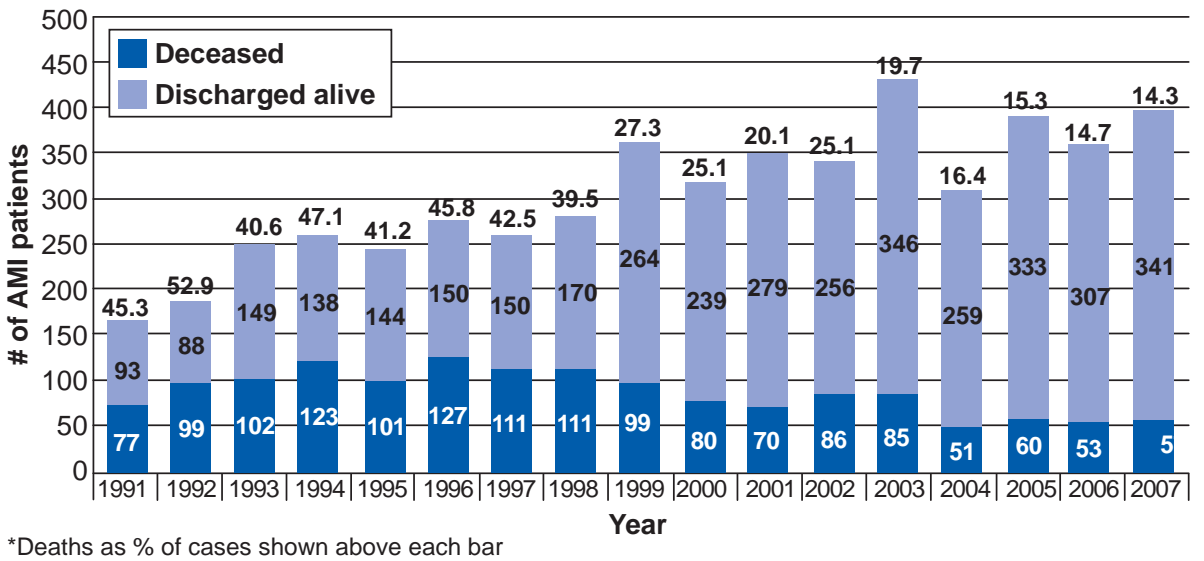


Changes in therapy As part of the CPG work, internationally recommended drugs of proven efficacy were used,[1,11-13] and efforts were made to inform and train hospital physicians in the their use. A post-intervention evaluation showed greater use of aspirin and beta blockers in 1999, associated with a significant drop in AMI hospital case fatality.[14,15]

A key therapy in AMI treatment is reperfusion $[6,11]$, and at HGAL the only reperfusion option available is thrombolysis. Recanalization of the artery associated with the infarction-if early, complete and maintained-improves prognosis, limits infarction size and preserves ventricular function. However, as a public health strategy, its effectiveness depends on its early use after onset of symptoms and the volume of patients who receive it. Cuban-manufactured recombinant streptokinase has been used at HGAL since 1994, although for the first three years, no change in case fatality was observed. Impediments to its optimal use were identified, subsequent efforts then focusing on reducing time between patient arrival at hospital and drug administration (door-to-drug time) and on treating the greatest number of patients possible.

In addition, continued monitoring of the percentage of patients receiving thrombolytics was included in HGAL's quality management strategy. During the past five years at time of writing, between $60 \%$ and $70 \%$ of AMI patients meeting eligibility criteria received thrombolytics, compared to $45 \%$ to $55 \%$ in the 1990 s. The authors consider that broad use of thrombolysis is the best AMI treatment alternative in developing countries, given its wider, near universal, availability; low cost; ease of administration and speed with which treatment can begin; and the fact that outcomes are less dependent on physician experience.

Furthermore, optimal use of the drugs described above and rapid hospital administration of thrombolytics are currently recognized as essential to AMI treatment[11] and are included among indicators for quality of hospital management of AMI.[16]

Organizational change To achieve the therapeutic goal, organizational change was also necessary. The first changes, related to thrombolysis optimization, were gradually introduced in1999 and 2000.[17] Their impact on door-to-drug periods and their possible determinants was assessed at four points in time (snapshots). The first two assessments (preintervention) — from February 11 through March 10, 1999 (snapshot I) and March 11 through April 10, 1999 (snapshot II)_revealed an average of 179 minutes from patient arrival at hospital to drug administration, far longer than the 40 minutes considered acceptable.[18] Main contributors to this delay were presentation of an atypical history, time taken to perform an electrocardiogram (a phenomenon commonly cited in the literature), and need for specialist assessment. No significant delays seen in other studies were associated with socioeconomic factors, age, skin color or sex.[11,19] After snapshot II, all chest pain was considered an emergency and given the highest treatment priority, but time taken to administer thrombolytics remained long, at 120 minutes (snapshot III, from April 11 through May 10, 1999). Thrombolysis location was then changed from the intensive care unit to the emergency department, cutting door-to-drug time to 53 minutes (snapshot IV, from July 9 through August 8, 1999). Subsequent measurements taken between October 1999 and May 2000 showed a gradual shortening of door-to-drug time to less than 35 minutes.
Two other organizational and structural changes were introduced for better AMI management. The first was the 1996 opening of the Emergency Intensive Care Unit as an emergency department area for advanced vital support, part of MINSAP's hospital revitalization strategy; this was followed in 1997 by SIUM accreditation in Cienfuegos. The second change was creation of the UCIC in March 2001 as part of the hospital's strategy for improved treatment of cardiovascular patients.

Prior to 2001, AMI patients were forced to make a tortuous circuit of the hospital.[20] Following their initial assessment in emergency services, they were admitted to the coronary section of the general ICU, located on the third floor, where they were monitored for 72 to 96 hours during the acute phase. Then they were transferred to the Intermediate Care Unit on the second floor, where they remained for another 48 hours. From there, they were moved to the cardiology service on the fourth floor, where they stayed until they had been hospitalized for a total of 10 days, at which point they were discharged.

Established in 2001, the UCIC consists of four contiguous sections on the same floor (intensive care, intermediate care, conventional hospitalization and the chest pain center). To measure impact of this reorganization, the hospital conducted a study[21] comparing two groups-a control group comprising all patients discharged with AMI nine months before the unit opened its doors and another group comprising those discharged nine months afterwards. A total of 1183 patients were studied, 578 before and 605 afterwards. Hospital case fatality for the institution as a whole was calculated, since lack of mechanisms for observing patients in hospital areas outside the UCIC, where AMI patients also die, may reduce chances of receiving appropriate and timely medical care and, hence, of survival. Average AMI hospital stay was significantly reduced after the UCIC opened (from $9.1 \pm 6.0$ days before to $6.7 \pm 2.3$ days after; $p=0.00$ ), a 2.4-day reduction. Moreover, a $7.9 \%$ reduction in hospital case fatality was observed after the unit opened (from $26.9 \%$ before to $19.0 \%$ after; $p=0.03$ ).[16]

It is also useful to have a unit for observation of patients with atypical chest pain. At HGAL this unit is an integral part of the UCIC. A prospective study two years after its 2001 opening[22] showed fewer diagnostic errors, fewer hospital admissions, and more appropriate use of diagnostic tests and available resources; in addition, $9.5 \%$ of the patients admitted required admission to intensive care, seven of them with $\mathrm{AMI}$ and one with primary ventricular fibrillation. The evidence currently supports creation of these units, for they not only reduce unnecessary admissions and costs but increase patient safety by improving cardiac diagnosis.[11]

\section{COMPREHENSIVE CARE}

It is recognized that medical care for AMI patients should be continuous and comprehensive to be successful. Improved survival involves addressing two critical aspects: treatment and rehabilitation-achieving better quality of life through individualized rehabilitation plans including diet, physical activity[23] and psychological support.[24-26] Cardiac rehabilitation is considered effective in reducing mortality.[27]

After the UCIC's opening in 2001, the psychological approach from early stages of AMI was introduced as a new concept in our medical care. In order to determine its impact, an interventional study was conducted from June 1, 2002 through May 31, 2003.[28] Patients 
were given relaxation, stimulation and sleep-inducing treatments, which showed positive impact on both the psychological and physiological parameters studied (heart rate, respiration rate and blood pressure). This coincides with findings that reducing negative emotions can help prevent cardiac arrhythmias, particularly in people with heart conditions, and that increasing positive emotions may have a positive impact on health.[26,29]

Other interventions to improve quality of care included training families in basic CPR, also considered necessary by international expert consensus,[11] and giving them a phone number to call for mobile emergency medical attention should pain or other symptoms suggestive of myocardial ischemia appear.

In June 1997, SIUM accreditation in Cienfuegos facilitated integration of mobile emergency care into PHC for AMI patients. This followed an extensive staff training and certification process that included basic and advanced courses in management of medical emergencies and trauma. It also involved conceptual, teaching, organizational and systemic changes in emergency management-changes that included prehospital triage and more cases handled in certain polyclinics and family medicine facilities equipped and designated as emergency-care centers, as well as initiating administration of thrombolytics in the PHC network.

Two studies were conducted that measured survival at one year after discharge. The first was a retrospective study and showed a survival rate of $71.4 \%$ in 1998.[30] The second, in 2005,[31] was a prospective study and showed a higher figure (78.3\%). In the later study, factors associated with higher case fatality were: female sex; history of diabetes mellitus, AMI with ST-elevation, failure to administer thrombolytics and failure to prescribe certain drugs of proven efficacy such as beta blockers, aspirin and ACE inhibitors. It should be underscored that HGAL does not have surgical revascularization options-such as angioplasty or bypass-at its disposal. Despite this, the net effect of actions tak- en as part of HGAL's institutional strategy for AMI was the reduction of case fatality by more than 25 percentage points over the decade.[5]

In principle, hospital management of AMI should aim to reduce case fatalities and emphasize secondary prevention. However, the authors consider a comprehensive approach best-in which all levels of care should participate, particularly PHC servicessince lowering mortality rates in large population groups depends largely on health promotion and disease prevention activities, staples of PHC's work. This thesis is supported by the fact that lower hospital case fatality is not correlated with AMI mortality rates.[2]

In order to continue the search for best evidence to inform better practices, since 1999 the AMI hospital team has been holding an annual national symposium to examine and compare trends in organizational practices and technologies as well as results in other institutions. The symposium has also strengthened collaboration between HGAL and both national institutes and $\mathrm{PHC}$ professionals in the province.

Finally, it should be noted that HGAL's UCIC has since received ISO 9001:2008 certification and level-2 hospital accreditation under the Cuban system, and its staff have been trained in advanced CPR.

\section{CONCLUSIONS}

Organizational changes, optimal use of drugs of proven efficacy, and good adherence to clinical practice guidelines as part of a strategy to improve hospital care led to reduced AMI hospital case fatality and could be related to improved survival in these patients. HGAL's experience supports inclusion of activities to improve comprehensive prevention and management of AMI patients in strategic hospital administration and quality assurance systems. $-\mathrm{W}$ -

\section{REFERENCES}

1. Gaziano MJ. Influencia global de la enfermedad cardiovascular. In: Braunwald. Cardiología Madrid: Harcourt Brace; 2006. p. 1-22. Spanish.

2. National Bureau of Medical Records and Health Statistics (CU). Series de tiempo de mortalidad. Havana: Ministry of Public Health (CU); 2011 Spanish.

3. Ordúñez $P$, Cooper RS, Espinosa AD, Iraola MD, Bernal JL, La Rosa Y. Enfermedades cardiovasculares en Cuba: determinantes para una epidemia y desafíos para la prevención y control. Rev Cubana Salud Pública. 2005;31(4):1-22. Spanish.

4. Rojas F. La salud pública revolucionaria cubana en su aniversario 50. Rev Cubana Salud Pública [Internet]. 2009 Jan-Mar [cited 2010 Oct 2];35(1). Available from: http://bvs.sld.cu/revi stas/spu/vol35_1_09/spu01109.htm. Spanish.

5. National Medical Sciences Information Center (CU). Hospital general Dr. Gustavo Aldereguía Lima. Informe estadístico 1990-2009 [Internet]. 2010 [cited 2010 Oct 2]. Available from: http:// www.gal.sld.cu/InformeEstadistico/EntradaSiste ma.php. Spanish.

6. De Vos $P$, Ordúñez $P O$, Santos $M$, Van der Stuyft P. Public hospital management in times of crisis: Lessons learned from Cienfuegos, Cuba (1996-2008). Health Policy [Internet]. 2010 Jun [cited 2010 Oct 2];96(1):64-71. Available from: http://www.healthpolicyjrnl.com/article/ S0168-8510\%2810\%2900012-2references
7. Viera B, del Sol LG, Espinosa AD, Espinosa AA Iraola MD. CMIC 2001[Internet]. [place unknown] [publisher unknown]; c2002. Evaluación de guías de buenas prácticas clínicas para diagnóstico y tratamiento del infarto miocárdico agudo. 2002 [cited 2010 Oct 2]; [about 9 p.]. Available from: http://www.uninet.edu/cimc2001/comunicaciones/ Mlraola/MIraola2/index.html. Spanish.

8. Falcón A, Vega R, Riverón F, Hernández AM, García JE. Evaluación de las guías de buenas prácticas clínicas en el Infarto Agudo del Miocardio. Enero -Mayo 2005. Hospital Gustavo Aldereguía Lima. XXIV Congreso Centroamericano de Cardiología [CD-ROM]. Havana: [publisher unknown]; 2006. ISBN 959-0282-23-7. Spanish.

9. Villanueva $\mathrm{N}$, Iraola MD, Falcón A, Fabregas F, Valladares F. Vía clínica en el infarto agudo del miocardio. Diseño, ensayo piloto y propuesta definitiva. Rev Calidad Asistencial 2005;20(3):140-51. Spanish.

10. Núñez L. Evaluación de la utilidad de la vía clínica en el manejo del Infarto agudo del miocardio [thesis]. [Cienfuegos]: Universidad de Ciencias Médicas; 2008. Spanish.

11. O'Connor RE, Bossaert L, Arntz HR, Brooks SC, Diercks D, Feitosa-Filho G, et al. Part 9: Acute coronary síndromes. 2010 International Consensus on Cardiopulmonary Resuscitation and Emergency Cardiovascular Care Science with Treatment Recommendations. Circulation. 2010 Oct 19;122(16 Suppl 2):S422-65.
12. Mehta S, Urban P, De Benedetti E. Acute Myocardial Infarction. Clinical Evidence. 2001:8-31.

13. Antman EM, Anbe DT, Amstrong PW, Bates ER Green LE, Hand M, et al. ACC/AHA guidelines for the management of patients with ST-elevation myocardial infarction - Executive summary: A report of the American College of Cardiology/ American Heart Association Task Force on Practice Guidelines (Writing Committee to Revise the 1999 Guidelines for the Management of Patients With Acute Myocardial Infarction). Circulation. 2004 Aug 3;110(5):588-636.

14. Iraola MD, Valladares FJ, Álvarez FC, Nodal JR, Rodríguez B. Optimización del tratamiento médico en el infarto agudo del miocardio. Rev Clínica Cardiovascular. 2000;18(3):11-6. Spanish.

15. Ordúñez P, Iraola M, La Rosa Y. Reducing mortality in myocardial infarction: experience in Cuba shows optimizing thrombolysis may reduce death rates in poor countries. BMJ. 2005 May 28;330(7502):1271-2.

16. Krumholz HM, Normand SL. Public reporting of 30-day mortality for patients hospitalized with acute myocardial infarction and heart failure. Circulation. 2008 Sep 23;118(13);1394-7.

17. Iraola MD. Calidad en Medicina de Emergencias. Rev Electron Biomed [Internet]. 2004 [cited 2010 Oct 2]; [about 30 p.]. Available from: http:// biomed.uninet.edu/2004/n1/mif.html. Spanish.

18. Terkelsen CJ, Lassen JF. Treatment delays in ST elevation myocardial infarction can be reduced 
by prehospital diagnosis and direct transfer to high volume catheterisation laboratories. BMJ. 2008 Feb 23;336(7641):401-2.

19. Gibler WB, Armstrong PW, Ohman EM, Weaver WD, Stebbins AL, Gore JM, et al. Persistence of delays in presentation and treatment for patients with acute myocardial infarction: The GUSTOI and GUSTO-III experience. Ann Emerg Med. 2002 Feb;39(2):123-30.

20. Navarro VR, Falcón A, Girau DM. Apuntes para la historia de los cuidados intensivos en Cienfuegos. Rev Cub Med Int Emerg [Internet] 2009 [cited 2010 Oct 2];8(2):1477-87. Available from: http://bvs.sld.cu/revistas/mie/vol8_2_09/ mie02209.pdf. Spanish.

21. Falcón A, Iraola MD, Valladares F, Orduñez P. Impacto de un nuevo servicio para la asistencia de enfermedades cardiovasculares agudas. Rev Cub Med Int Emerg. 2006;5(2):380-90. Spanish.

22. Viera B, Iraola MD, Valladares F. Pacientes admitidos en el centro de dolor toráxico. Resultados de un año de estudio. Rev Cub Med Int Emerg [Internet]. 2005 [cited 2010 Oct 2];5(23):[1-8]. Available from: http://bvs.sld.cu/revistas/mie/vol4_2-3_05/mie06205.htm. Spanish.

23. Navarro JJ, Vega RS, González C, Rodríguez T. Rehabilitación cardiovascular. Resultados en el servicio de Cardiología. MediSur [Internet]. 2004 [cited 2010 Oct 2];2(1):23-7. Available from: http://www.medisur.sld.cu/index.php/medisur/ article/view/39. Spanish.

24. Ades PA. Cardiac rehabilitation and secondary prevention of coronary heart disease. $\mathrm{N}$ Engl J Med. 2001 Sep 20;345(12):892-902.

25. Alter DA, Oh PI, Chong A. Relationship between cardiac rehabilitation and survival after acute cardiac hospitalization within a universal healthcare system. Eur J Cardiovasc Prev Rehabil. 2009 Feb;16(1):102-13.

26. Camm AJ, Lüscher TF, Serruys PW, editors Cardiac rehabilitation. The ESC textbook of cardiovascular medicine. Oxford (UK): Oxford University Press; 2009. $1122 \mathrm{p}$

27. Suaya JA, Stason WB, Ades PA, Normand SL, Shepard DS. Cardiac rehabilitation and survival in older coronary patients. J Am Coll Cardiol. 2009 Jun 30;54(1):25-33.

28. Rodríguez T, Navarro JJ. Sistema de influencias psicoterapéuticas en pacientes con afecciones cardiovasculares hospitalizados. MediSur [Internet]. 2004 [cited 2010 Oct 2];2(1):28-34. Available from: http://www.medisur.sld.cu/index.php/ medisur/article/view/40. Spanish.

29. Stewart RA, North FM, West TM, Sharples KJ, Simes RJ, Colguhoun DM, et al. Depression and cardiovascular morbidity and mortality: cause or consequence. Eur Heart J. 2003 Nov;24(22):2027-37.

30. Iraola MD, Santana AA, Rodríguez B, Valladares FJ. Sobrevida en el infarto agudo del miocardio. Rev Clínica Cardiovascular. 2001;19(2):40-5 Spanish.

31. Falcón A. Determinantes de la supervivencia al año de pacientes con Infarto Miocárdico Agudo [thesis]. [Cienfuegos (CU)]: Medical Sciences University of Cienfuegos (CU); 2008. Spanish.

\section{Authors}

Víctor René Navarro Machado (Corresponding author: victor.navarro@gal.sld.cu). Dual specialist in internal medicine and emergency medicine, with a doctorate in health sciences. Associate professor and researcher, Dr Gustavo Aldereguía Lima University General Hospita (HGAL), Cienfuegos, Cuba.

Arelys Falcón Hernández, dual specialist in internal and emergency medicine with a master's degree in emergency medicine. Assistent professor and associate researcher, HGAL, Cienfuegos, Cuba.

Marcos D. Iraola Ferrer, dual specialist in internal and emergency medicine with a master's degree in emergency medicine. Instructor, HGAL, Cienfuegos, Cuba

Francisco Valladares Carvajal, cardiologist with a master's degree in emergency medicine. Assistant professor and adjunct researcher HGAL, Cienfuegos, Cuba.

Pedro O. Orduñez García, internist specializing in public health with a doctorate in health sciences. Professor of Medicine and Public Health National School of Public Health. Advisor, chronic disease prevention and control, $\mathrm{PAHO}$ WHO, Washington, DC.

Submitted: September 27, 2011

Approved for publication: September 21, 2012 Disclosures: None 